\title{
Understanding and targeting centrally mediated visceral pain in inflammatory bowel disease
}

\author{
Kristen E. Farrell' ${ }^{1}$ Robert J. Callister ${ }^{1}$ and Simon Keely ${ }^{1,2 *}$ \\ 1 School of Biomedical Sciences and Pharmacy, The University of Newcastle, Callaghan, NSW, Australia \\ ${ }^{2}$ Gastrointestinal Research Group, Viruses, Infection/Immunity, Vaccines and Asthma Program, Hunter Medical Research Institute, New Lambton Heights, NSW, \\ Australia \\ *Correspondence: simon.keely@newcastle.edu.au
}

Edited by:

Susan Hua, The University of Newcastle, Australia

Reviewed by:

Bruno Bonaz, Grenoble Faculty of Medicine and Hospital, France

Matthew W. Carroll, University of Alberta, Canada

Rajaraman D. Eri, University of Tasmania, Australia

Keywords: inflammatory bowel diseases, colitis, visceral pain, spinal cord, central sensitization

Chronic abdominal pain is a debilitating symptom of inflammatory bowel disease (IBD): a chronic inflammatory condition of the gastrointestinal tract, which includes Crohn's disease (CD) and ulcerative colitis (UC), and is characterized by periods of inflammation and remission. During inflammation, pain is often present due to the activation of afferent nerve endings in the gut by inflammatory mediators (Beyak and Vanner, 2005). Importantly, pain associated with IBD often persists after inflammation has resolved, based on clinical and endoscopic examination, and is often "referred" from the gut to cutaneous or other visceral regions (Minderhoud et al., 2004). Based on what we know about pain processing circuits, this suggests the source of chronic and referred pain lies within the central nervous system (CNS). These clinical observations are supported by work in animal models of visceral inflammation that have provided behavioral, anatomical, molecular, and physiological evidence to implicate spinal circuits in the development of altered pain responses in IBD (Farrell et al., 2014). In spite of this evidence, little is known about the precise mechanisms of chronic pain development and maintenance in IBD. This lack of understanding severely limits current therapeutic approaches for IBD pain management.

\section{PAIN MANAGEMENT IN IBD}

Abdominal pain is a common symptom of IBD, with up to $70 \%$ of patients presenting with pain during disease onset, or during periods of relapse (Wagtmans et al., 1998). Pain is an indicator of inflammation, and in the case of IBD, occurs in response to the sensitization of intestinal sensory neurons by inflammatory cytokines. Importantly, inflammation does not appear to be the sole cause of pain in IBD, as $30-50 \%$ of patients in clinical remission (i.e., no detectable inflammation in the gut) continue to experience severe abdominal pain (Minderhoud et al., 2004; Farrokhyar et al., 2006; Siegel and MacDermott, 2009). The lack of effective pain management for this patient cohort is problematic in its own right, but is also associated with significantly decreased health-related quality of life scores, increased stress, anxiety, and depression (Farrokhyar et al., 2006; Schirbel et al., 2010). As a consequence, a significant number of IBD patients are chronically treated with narcotics (Edwards et al., 2001; Cross et al., 2005; Makharia, 2011). Unfortunately, longterm narcotic use gives rise to a range of side effects in IBD patients, such as nausea, reduced gastrointestinal motility, and narcotic bowel syndrome; i.e., increased abdominal pain despite escalating narcotic use. These detrimental effects worsen with continued drug use (Grunkemeier et al., 2007), yet the use of narcotics persists, especially for IBD patients during hospitalization and surgery associated with relapse (Lian et al., 2010; Long et al., 2012). These issues are compounded by the lack of alternative pain management therapies, as analgesics such as non-steroidal anti-inflammatory drugs (NSAIDS), including selective COX-2 inhibitors, are linked to disease exacerbation (Bielefeldt et al., 2009; Srinath et al., 2012). Given the lack of options and efficacy issues with current pharmaceutics, it is not surprising that narcotic addiction is a major problem in IBD. Rates of narcotic addiction are over $5 \%$ in Crohn's patients and $2.7 \%$ overall in IBD patients (Edwards et al., 2001), with the risk increased by 8 -fold in those patients with concurrent psychiatric disorders, including depression, anxiety, sexual, emotional and physical abuse and substance abuse (Edwards et al., 2001; Hanson et al., 2009). Thus, there is critical need for new approaches and therapies for IBD pain management. However, before new therapeutics can be designed, the mechanisms responsible for the development and maintenance of chronic abdominal pain in IBD must be understood.

\section{SENSORY TRANSMISSION IN THE GASTROINTESTINAL TRACT}

The gastrointestinal tract is unique as its function is regulated by both intrinsic and extrinsic components of the autonomic nervous system. Intrinsic innervation is controlled by the enteric nervous system (ENS), which consists of connecting nerve plexuses that run between the muscular layers and the submucosa of the gut wall. The ENS controls gastrointestinal motility, secretion and absorption, which are all essential for gut function, but plays no major role in pain transmission (Blackshaw et al., 2007).

The extrinsic innervation of the gastrointestinal tract includes efferent 
parasympathetic and sympathetic autonomic pathways that are involved in the modulation of ENS activity. There are also extrinsic sensory afferents that convey information, including (but not exclusive to) noxious (potentially painful) and innocuous sensations, to the spinal cord and brainstem. Brookes et al. have compiled a comprehensive review of extrinsic sensory afferent types that innervate the gut wall (Brookes et al., 2013). Sensory afferents convey signals (including noxious signals that cause pain) from the lower gastrointestinal tract to the CNS via two major nerve trunks, the splanchnic and pelvic nerves (Gebhart, 2000; Blackshaw et al., 2007). These nerves enter the CNS via the spinal cord dorsal horn, where sensory information is subject to extensive modulation via local interneuron networks and descending influences (Melzack and Wall, 1965). Finally, signals from the gut ascend to the cortex via several pathways, including the spinothalamic, spinoreticular and spinomesencephalic tracts, where perception can occur (Craig, 2002; Jones et al., 2006).

\section{ALTERED NERVOUS SYSTEM SIGNALING IN IBD-RELATED PAIN}

There is a growing body of evidence from animal studies, suggesting that a dysfunction of the nervous system plays a role in the development of a chronic pain state in IBD (Willis and Westlund, 1997; Gebhart, 1999; Hughes et al., 2009). Most research on the neural mechanisms responsible for pain in IBD has focused on the peripheral nervous system, where strong evidence of hyperexcitability in afferent nerves has been documented. For example, in animal models of chemically induced colitis, hypersensitivity of mechanosensitive sensory afferents following inflammation has been demonstrated, with reduced thresholds for activation and increased frequencies of action potential discharge reported (Hughes et al., 2009; Feng et al., 2012). Importantly, this hypersensitivity is sustained following recovery from inflammation, which may be a contributing factor in the development of chronic pain (Hughes et al., 2009; Feng et al., 2012).

Other work has shown that colonic inflammation can result in increased behavioral responses to mechanical distension and intraluminal administration of capsaicin into the colon, and that this hypersensitivity can be reversed by antagonism of TRPV1 ion channels, implicating TRPV1 expression in the development of peripheral hyperalgesia (Miranda et al., 2007). Taken together, these data indicate that after colonic inflammation, sensory afferents can become hypersensitive to both mechanical and chemical stimulation, and this can be attributed, at least in part, to changes in the expression of ion channels within sensory afferents.

Although the evidence for peripheral contributions to colonic hypersensitivity is strong, the existence of referred pain in IBD patients and in animal models of colitis suggests the CNS, particularly the spinal cord dorsal horn, is implicated in the development of abnormal pain, as referred pain cannot be explained by hypersensitive colon afferents alone (Bernstein et al., 1996). Referred pain is a common sequelae of visceral pain, in which diffuse, poorly localized pain from the viscera "referred" to other areas: most often to the skin (Cervero and Laird, 1999). For IBD, pain is often referred to the midlower back, abdomen, and legs (Ritchie, 1973; Ness et al., 1990; Accarino et al., 1995; Bernstein et al., 1996) and, not surprisingly, is a source of great discomfort. It is thought that referred pain occurs when there is overlap between visceral and somatic pathways within the CNS (Traub, 2000). The region of the CNS where this cross over is most likely to occur is within the spinal cord dorsal horn, as the dorsal horn receives inputs from skin, joints and muscle as well as from the viscera (Almeida et al., 2004).

Evidence that the CNS is involved in the processing of inflammation-induced visceral pain has been demonstrated in animal models at behavioral, anatomical, molecular, and physiological levels of analysis (Farrell et al., 2014). Briefly, it has been shown that animals develop referred hypersensitivity of the hind paw and abdomen following colitis (Lamb et al., 2006), and that this sensitivity remains after the resolution of inflammation (Eijkelkamp et al., 2009). Likewise, colitis results in increased dorsal horn expression of markers of neural activation (cFos and pERK) following distension
(Traub and Murphy, 2002; Harrington et al., 2012), as well as neuropeptides commonly linked with pain signaling, such as Substance P and CGRP (Sun and Luo, 2004). Finally, the excitability of spinal dorsal horn neurons has been shown to increase following colitis, with extracellular recordings demonstrating a decrease in action potential threshold and increases in spontaneous neural activity (Al-Chaer et al., 1997). We have previously presented a systematic review outlining the evidence for altered CNS activity following gastrointestinal inflammation (Farrell et al., 2014).

Magnetic resonance imaging studies have also demonstrated changes in the structure and functional activation of cortical and subcortical regions in IBD patients compared with healthy controls. Using fMRI, patients with IBD were shown to have differing patterns of cortical activation and deactivation in response to noxious rectal balloon distension (Bernstein et al., 2002). Likewise, CD patients exhibit altered gray matter volumes in cortical (frontal and anterior midcingulate corticies) and subcortical regions that are associated with emotion, cognition, and nociception (Agostini et al., 2013). Therefore, there is evidence for both spinal and supra-spinal alterations as a consequence of chronic pain in IBD.

\section{FUTURE ADVANCES IN IBD PAIN MANAGEMENT}

The presence of chronic pain in IBD patients represents a major health burden, as it can impact significantly on the quality of life and mental health of long-term sufferers. Current pain management strategies are not optimal: often ineffective and associated with a number of detrimental off-target effects (Edwards et al., 2001; Hanson et al., 2009; Siegel and MacDermott, 2009; Srinath et al., 2012). Recent studies have demonstrated that targeting specific CNS pathways could alleviate visceral pain in animal models. For instance, targeting of central N-methyl-D-aspartate (NMDA) receptors is of particular interest, as there is strong evidence for spinal NMDA receptor-dependent neurotransmission underling the development of central sensitization (Haley et al., 1990; Ren et al., 1992). In models of colonic 
inflammation, microinjection of the NMDA receptor antagonist DL-2-amino5-phosphonovaleric acid (APV) into the rostral ventromedial medulla (RVM) was shown to attenuate exaggerated behavioral responses to colon distension. This attenuation was not observed for injections outside the RVM (Coutinho et al., 1998). Since spinal nociceptive transmission is subject to modulation from supraspinal sites such as the RVM, this demonstrates that visceral hyperalgesia can be influenced by NMDA-dependent descending pain modulation. Likewise, cross-organ sensitization between the inflamed colon and the urethra was reversed by intrathecal injection of APV, and by antagonism NR2B: a subunit of the NMDA receptor, using Co-101244 (Peng et al., 2009). Therefore, direct antagonism of spinal NMDA receptors, specifically the NR2B subunit, can attenuate central sensitization caused by inflammation of the colon.

Another potential candidate recently investigated for visceral pain management is the nociceptive ion channel TPVR1. TRPV1 channels are activated by heat ( $>$ $43^{\circ}$ ) and capsasin (Christoph et al., 2006) and are expressed in up to $80 \%$ of visceral afferents (vs. less than one third in somatic afferents) (Robinson and Gebhart, 2008). This makes these channels an appealing pharmacological target. Silencing of TRPV1 in the CNS using intrathecal injection of TRPV1-specific siRNA 4 days prior to intrarectal capsaicin administration was shown to reduce capsasin-induced spontaneous pain behaviors in rats (Christoph et al., 2006). Importantly, in models of neuropathic pain, TRPV1-specific siRNA analgesia could be maintained for 4-5 days (Christoph et al., 2006). Interestingly, the siRNA used, VsiR1, is directed against a segment of TRPV1 mRNA that is conserved in mouse, rat and human, suggesting this approach may be easily translatable into humans.

Although new CNS targets for managing chronic visceral pain are emerging, the blood brain barrier represents a continual obstacle in the development of new therapeutics. The blood brain barrier presents physical, transport and metabolic barriers that can be modulated and regulated under both normal and pathological states (Abbott et al., 2010). Direct intrathecal injection of therapeutics is the most direct way to bypass these barriers, however, it is by far the least practical solution in a clinical setting. Importantly, recent advances in nanoparticle carrier technologies may allow better targeting of CNS pathways involved in visceral pain through sitedirected drug delivery and enhanced penetration of the blood brain barrier (Hua and Wu, 2013).

In summary, visceral pain in chronic inflammatory diseases is poorly understood and current therapeutic strategies are limited. Further research is required to improve our knowledge of the events leading to the development chronic visceral pain. In addition, the discovery of improved CNS targets for pain management along with improved methods for drug delivery, are urgently required for the management IBD patients with chronic pain.

\section{ACKNOWLEDGMENTS}

This work was supported by grants form from the National Health and Medical Research Council of Australia (APP1021582 to Simon Keely, APP1067146 to Robert J. Callister and Simon Keely), the Hunter Medical Research Institute and the University of Newcastle Priority Research Centre for Translational Neuroscience.

\section{REFERENCES}

Abbott, N. J., Patabendige, A. A., Dolman, D. E., Yusof, S. R., and Begley, D. J. (2010). Structure and function of the blood-brain barrier. Neurobiol. Dis. 37, 13-25. doi: 10.1016/j.nbd.2009. 07.030

Accarino, A. M., Azpiroz, F., and Malagelada, J. R. (1995). Selective dysfunction of mechanosensitive intestinal afferents in irritable bowel syndrome. Gastroenterology 108, 636-643. doi: 10.1016/00165085(95)90434-4

Agostini, A., Benuzzi, F., Filippini, N., Bertani, A., Scarcelli, A., Farinelli, V., et al. (2013). New insights into the brain involvement in patients with Crohn's disease: a voxel-based morphometry study. Neurogastroenterol. Motil. 25, 147-e82. doi: 10.1111/nmo.12017

Al-Chaer, E. D., Westlund, K. N., and Willis, W. D. (1997). Sensitization of postsynaptic dorsal column neuronal responses by colon inflammation. Neuroreport 8, 3267-3273. doi: 10.1097/00001756199710200-00016

Almeida, T. F., Roizenblatt, S., and Tufik, S. (2004). Afferent pain pathways: a neuroanatomical review. Brain Res. 1000, 40-56. doi: 10.1016/j.brainres.2003.10.073

Bernstein, C. N., Frankenstein, U. N., Rawsthorne, P., Pitz, M., Summers, R., and McIntyre, M. C. (2002). Cortical mapping of visceral pain in patients with
GI disorders using functional magnetic resonance imaging. Am. J. Gastroenterol. 97, 319-327. doi: 10.1111/j.1572-0241.2002.05464.x

Bernstein, C. N., Niazi, N., Robert, M., Mertz, H., Kodner, A., Munakata, J., et al. (1996). Rectal afferent function in patients with inflammatory and functional intestinal disorders. Pain 66, 151-161. doi: 10.1016/0304-3959(96)03062-X

Beyak, M. J., and Vanner, S. (2005). Inflammationinduced hyperexcitability of nociceptive gastrointestinal DRG neurones: the role of voltagegated ion channels. Neurogastroenterol. Motil. 17, 175-186. doi: 10.1111/j.1365-2982.2004.00596.x

Bielefeldt, K., Davis, B., and Binion, D. G. (2009). Pain and inflammatory bowel disease. Inflamm. Bowel Dis. 15, 778-788. doi: 10.1002/ibd.20848

Blackshaw, L. A., Brookes, S. J., Grundy, D., and Schemann, M. (2007). Sensory transmission in the gastrointestinal tract. Neurogastroenterol. Motil. 19, 1-19. doi: 10.1111/j.1365-2982.2006.00871.x

Brookes, S. J., Spencer, N. J., Costa, M., and Zagorodnyuk, V. P. (2013). Extrinsic primary afferent signalling in the gut. Nat. Rev. Gastroenterol. Hepatol. 10, 286-296. doi: 10.1038/nrgastro.2013.29

Cervero, F., and Laird, J. M. (1999). Visceral pain. Lancet 353, 2145-2148. doi: 10.1016/S01406736(99)01306-9

Christoph, T., Grunweller, A., Mika, J., Schafer, M. K., Wade, E. J., Weihe, E., et al. (2006). Silencing of vanilloid receptor TRPV1 by RNAi reduces neuropathic and visceral pain in vivo. Biochem. Biophys. Res. Commun. 350, 238-243. doi: 10.1016/j.bbrc.2006.09.037

Coutinho, S. V., Urban, M. O., and Gebhart, G. F. (1998). Role of glutamate receptors and nitric oxide in the rostral ventromedial medulla in visceral hyperalgesia. Pain 78, 59-69. doi: 10.1016/S0304-3959(98)00137-7

Craig, A. D. (2002). How do you feel? Interoception: the sense of the physiological condition of the body. Nat. Rev. Neurosci. 3, 655-666. doi: 10.1038/nrn894

Cross, R. K., Wilson, K. T., and Binion, D. G. (2005). Narcotic use in patients with Crohn's disease. Am. J. Gastroenterol. 100, 2225-2229. doi: 10.1111/j.1572-0241.2005.00256.x

Edwards, J. T., Radford-Smith, G. L., and Florin, T. H. (2001). Chronic narcotic use in inflammatory bowel disease patients: prevalence and clinical characteristics. J. Gastroenterol. Hepatol. 16, 1235-1238. doi: 10.1046/j.1440-1746.2001.02468.x

Eijkelkamp, N., Heijnen, C. J., Elsenbruch, S., Holtmann, G., Schedlowski, M., and Kavelaars, A. (2009). G protein-coupled receptor kinase 6 controls post-inflammatory visceral hyperalgesia. Brain Behav. Immun. 23, 18-26. doi: 10.1016/j.bbi.2008.07.006

Farrell, K. E., Keely, S., Graham, B. A., Callister, R., and Callister, R. J. (2014). A systematic review of the evidence for central nervous system plasticity in animal models of inflammatory-mediated gastrointestinal pain. Inflamm. Bowel Dis. 20, 176-195. doi: 10.1097/01.MIB.0000437499.52922.b1

Farrokhyar, F., Marshall, J. K., Easterbrook, B., and Irvine, E. J. (2006). Functional gastrointestinal disorders and mood disorders in patients 
with inactive inflammatory bowel disease: prevalence and impact on health. Inflamm. Bowel Dis. 12, 38-46. doi: 10.1097/01.MIB.0000195391. 49762.89

Feng, B., La, J. H., Schwartz, E. S., Tanaka, T., McMurray, T. P., and Gebhart, G. F. (2012). Long-term sensitization of mechanosensitive and -insensitive afferents in mice with persistent colorectal hypersensitivity. Am. J. Physiol. Gastrointest. Liver Physiol. 302, G676-G683. doi: 10.1152/ajpgi.00490.2011

Gebhart, G. F. (1999). Peripheral contributions to visceral hyperalgesia. Can. J. Gastroenterol. 13 (Suppl. A), 37A-41A.

Gebhart, G. F. (2000). Visceral pain-peripheral sensitisation. Gut 47 (Suppl. 4), iv54-iv55. discussion: iv58. doi: 10.1136/gut.47.suppl_4.iv54

Grunkemeier, D. M., Cassara, J. E., Dalton, C. B., and Drossman, D. A. (2007). The narcotic bowel syndrome: clinical features, pathophysiology, and management. Clin. Gastroenterol. Hepatol. 5, 1126-1139; quiz 1121-1122. doi: 10.1016/j.cgh.2007.06.013

Haley, J. E., Sullivan, A. F., and Dickenson, A. H. (1990). Evidence for spinal N-methyl-D-aspartate receptor involvement in prolonged chemical nociception in the rat. Brain Res. 518, 218-226. doi: 10.1016/0006-8993(90)90975-H

Hanson, K. A., Loftus, E. V. Jr., Harmsen, W. S., Diehl, N. N., Zinsmeister, A. R., and Sandborn, W. J. (2009). Clinical features and outcome of patients with inflammatory bowel disease who use narcotics: a case-control study. Inflamm. Bowel Dis. 15, 772-777. doi: 10.1002/ibd.20847

Harrington, A. M., Brierley, S. M., Isaacs, N., Hughes, P. A., Castro, J., and Blackshaw, L. A. (2012). Sprouting of colonic afferent central terminals and increased spinal mitogen-activated protein kinase expression in a mouse model of chronic visceral hypersensitivity. J. Comp. Neurol. 520, 2241-2255. doi: $10.1002 /$ cne. 23042

Hua, S., and Wu, S. Y. (2013). The use of lipidbased nanocarriers for targeted pain therapies. Front. Pharmacol. 4:143. doi: 10.3389/fphar.2013. 00143

Hughes, P. A., Brierley, S. M., Martin, C. M., Brookes, S. J., Linden, D. R., and Blackshaw, L. A. (2009). Post-inflammatory colonic afferent sensitisation: different subtypes, different pathways and different time courses. Gut 58, 1333-1341. doi: 10.1136/gut.2008.170811

Jones, M. P., Dilley, J. B., Drossman, D., and Crowell, M. D. (2006). Brain-gut connections in functional GI disorders: anatomic and physiologic relationships. Neurogastroenterol. Motil. 18, 91-103. doi: 10.1111/j.1365-2982.2005.00730.x

Lamb, K., Zhong, F., Gebhart, G. F., and Bielefeldt, K. (2006). Experimental colitis in mice and sensitization of converging visceral and somatic afferent pathways. Am. J. Physiol. Gastrointest. Liver Physiol. 290, G451-G457. doi: 10.1152/ajpgi.00353.2005

Lian, L., Fazio, V. W., Hammel, J., and Shen, B. (2010). Impact of narcotic use on the requirement for colectomy in inpatients with ulcerative colitis. Dis. Colon Rectum 53, 1295-1300. doi: 10.1007/DCR.0b013e3181e7562c

Long, M. D., Barnes, E. L., Herfarth, H. H., and Drossman, D. A. (2012). Narcotic use for inflammatory bowel disease and risk factors during hospitalization. Inflamm. Bowel Dis. 18, 869-876. doi: 10.1002/ibd.21806

Makharia, G. K. (2011). Understanding and treating abdominal pain and spasms in organic gastrointestinal diseases: inflammatory bowel disease and biliary diseases. J. Clin. Gastroenterol. 45 (Suppl.), S89-S93. doi: 10.1097/MCG.0b013e31821fbd82

Melzack, R., and Wall, P. D. (1965). Pain mechanisms: a new theory. Science 150, 971-979. doi: 10.1126/science.150.3699.971

Minderhoud, I. M., Oldenburg, B., Wismeijer, J. A., van Berge Henegouwen, G. P., and Smout, A. J. (2004). IBS-like symptoms in patients with inflammatory bowel disease in remission; relationships with quality of life and coping behavior. Dig. Dis. Sci. 49, 469-474. doi: 10.1023/B:DDAS.0000020506.84248.f9

Miranda, A., Nordstrom, E., Mannem, A., Smith, C., Banerjee, B., and Sengupta, J. N. (2007). The role of transient receptor potential vanilloid 1 in mechanical and chemical visceral hyperalgesia following experimental colitis. Neuroscience 148, 1021-1032. doi: 10.1016/j.neuroscience.2007.05.034

Ness, T. J., Metcalf, A. M., and Gebhart, G. F. (1990). A psychophysiological study in humans using phasic colonic distension as a noxious visceral stimulus. Pain, 43, 377-386. doi: 10.1016/03043959(90)90035-C

Peng, H.-Y., Chen, G.-D., Tung, K.-C., Lai, C.Y., Hsien, M.-C., Chiu, C.-H., et al. (2009). Colon mustard oil instillation induced crossorgan reflex sensitization on the pelvic-urethra reflex activity in rats. Pain 142, 75-88. doi: 10.1016/j.pain.2008.11.017

Ren, K., Hylden, J. L., Williams, G. M., Ruda, M. A., and Dubner, R. (1992). The effects of a non-competitive NMDA receptor antagonist, MK801 , on behavioral hyperalgesia and dorsal horn neuronal activity in rats with unilateral inflammation. Pain 50, 331-344. doi: 10.1016/03043959(92)90039-E

Ritchie, J. (1973). Pain from distension of the pelvic colon by inflating a balloon in the irritable colon syndrome. Gut 14, 125-132. doi: 10.1136/gut.14.2.125

Robinson, D. R., and Gebhart, G. F. (2008). Inside information: the unique features of visceral sensation. Mol. Interv. 8, 242-253. doi: 10.1124/mi.8.5.9
Schirbel, A., Reichert, A., Roll, S., Baumgart, D. C., Buning, C., Wittig, B., et al. (2010) Impact of pain on health-related quality of life in patients with inflammatory bowel disease. World J. Gastroenterol. 16, 3168-3177. doi: 10.3748/wjg.v16.i25.3168

Siegel, C. A., and MacDermott, R. P. (2009). Is chronic pain an extraintestinal manifestation of IBD? Inflamm. Bowel Dis. 15, 769-771. doi: 10.1002/ibd.20844

Srinath, A. I., Walter, C., Newara, M. C., and Szigethy, E. M. (2012). Pain management in patients with inflammatory bowel disease: insights for the clinician. Therap. Adv. Gastroenterol. 5, 339-357. doi: $10.1177 / 1756283 \mathrm{X} 12446158$

Sun, Y.-N., and Luo, J.-Y. (2004). Effects of tegaserod on Fos, substance $\mathrm{P}$ and calcitonin gene-related peptide expression induced by colon inflammation in lumbarsacral spinal cord. World J. Gastroenterol. 10, 1830-1833.

Traub, R. J. (2000). Evidence for thoracolumbar spinal cord processing of inflammatory, but not acute colonic pain. Neuroreport 11 , 2113-2116. doi: 10.1097/00001756-20000714000011

Traub, R. J., and Murphy, A. (2002). Colonic inflammation induces fos expression in the thoracolumbar spinal cord increasing activity in the spinoparabrachial pathway. Pain 95, 93-102. doi: 10.1016/S0304-3959(01)00381-5

Wagtmans, M. J., Verspaget, H. W., Lamers, C. B., and van Hogezand, R. A. (1998). Crohn's disease in the elderly: a comparison with young adults. J. Clin. Gastroenterol. 27, 129-133. doi: 10.1097/00004836-199809000-00005

Willis, W. D., and Westlund, K. N. (1997). Neuroanatomy of the pain system and of the pathways that modulate pain. J. Clin. Neurophysiol. 14, 2-31. doi: 10.1097/00004691-19970100000002

Received: 14 January 2014; accepted: 13 February 2014; published online: 05 March 2014.

Citation: Farrell KE, Callister RJ and Keely S (2014) Understanding and targeting centrally mediated visceral pain in inflammatory bowel disease. Front. Pharmacol. 5:27. doi: 10.3389/fphar.2014.00027

This article was submitted to Neuropharmacology, a section of the journal Frontiers in Pharmacology. Copyright (c) 2014 Farrell, Callister and Keely. This is an open-access article distributed under the terms of the Creative Commons Attribution License (CC BY). The use, distribution or reproduction in other forums is permitted, provided the original author(s) or licensor are credited and that the original publication in this journal is cited, in accordance with accepted academic practice. No use, distribution or reproduction is permitted which does not comply with these terms. 